\title{
THE PROPOSAL OF GIVING TWO RECEIPTS FOR VOTERS TO INCREASE THE SECURITY OF ELECTRONIC VOTING
}

\author{
Abbas Akkasi ${ }^{1}$, Ali Khaleghi ${ }^{2}$, Mohammad Jafarabad ${ }^{3}$, Hossein Karimi ${ }^{4}$, \\ Mohammad Bagher Demideh ${ }^{5}$ and Roghayeh Najjari Alamuti ${ }^{6}$ \\ ${ }^{1,3}$ Young Researchers Club, Robatkarim Branch, \\ Islamic Azad University, RobatKarim, Iran \\ abbas.akkasi@gmail.com \\ jafarabadm@yahoo.com \\ ${ }^{2}$ Department of Computer Engineering, \\ Imam Khomeini International University, Qazvin, Iran \\ Akhaleghi@eng.ikiu.ac.ir \\ ${ }^{4}$ Sama Technical and Vocational Training College, \\ Islamic Azad University, Yasouj Branch, Yasuj, IRAN \\ H.karimi.esf@gmail.com \\ ${ }^{5}$ Faculty of Engineering, Department of Computer, Yasouj Branch, Islamic \\ Azad University, Kohgiloyeh \& Bovirahmad Province, Yasouj, iran \\ M.b.damideh@gmail.com \\ ${ }^{6}$ Department of Computer Engineering, \\ Imam Khomeini International University, Qazvin, Iran \\ S936369006@edu.ikiu.ac.ir
}

\begin{abstract}
Holding an election with aim of selecting only one person or approval / rejection of a state law, is a special kind of election which every few years in the different countries going to happen. Given the pervasiveness of this election, we must take special measures to provide high security for the referendum. Using two receipts for each voter which one is named barcode receipt, a secret indicator of vote and another is named key receipt that is a key to acknowledged the voters information box, including: voter's National Code, the candidate code which is voted by this voter, code of election station and barcode information. In this paper is proposed to enable people and social networks using data on bar code's receipts without Intrusion into the privacy of other voters, so they will put together their personal information from monitoring the election process on a social network which can help to prevent any violation in election. The security of the proposed scheme is based on the turnout in recount of votes.
\end{abstract}

\section{KEYWORDS}

Election Transparency, Electronic Referendum, Barcode Receipt

\section{INTRODUCTION}

There are various methods of conducting elections in the world. Some countries do their election in multi stage, like India that because of its multi billion population, has more than 10 stages for each election. [1] However, in some countries because of low population, elections are held every Natarajan Meghanathan et al. (Eds) : WiMONe, NCS, SPM, CSEIT - 2014 pp. 37-41, 2014. @ CS \& IT-CSCP 2014

DOI : $10.5121 / \mathrm{csit} .2014 .41204$ 
few years. There are diversities for voting procedures, including voting at an annual meeting of the 10 persons to voting in a country that contain all people. One of the most common methods of voting is a way in which the entire population of the country with a minimum age requirement can participate in the election, and finally an option as the end result will be choose which that option has more votes in compared with other options. For example, this option can be elected a president from among 10 candidates for the Presidential Election, or approval of, or opposition to a government's decision. [1]

In this article we're going to review the election with the same Candidates for the entire country so we must select one option certainly. Accordingly, the possibility of holding such elections in each country is once or twice, annually or in every few years. For example, in Iran an election with these terms will be held once every 4 years. Therefore, any simple proposal without logical thinking and foresight, finally up to a period of several years will respond to the voting system, then because of the passage of time and the arrival of more advanced systems, its use would be without benefit plan or it will be failed. In this article we're going to have an idea for the elections in the countries that will be held in the form of a referendum, stating that at least in the next 20 years to meet the electoral needs of the country. Our favorite is the plan that makes it possible to hold the elections with the cost affordable and few times in the year, which in this situation government can get help by people's comments in critical decisions with holding an quick electronic election, It improves economic, political and social conditions of the country.[2]

\section{REVIEW THE POSSIBLE ELECTION SCENARIOS}

The conventional method in Iran is the same as the traditional method of election,which we use of Fund votes and finally collect in the presence of observers, votes cast in the ballot box, are counted. the election observers (government and candidates observers) from the moment of the initial closure of the Fund's voting to stage that open ballot boxes and counting of votes ,must be present in the Polling place, given that it's difficult to be sure that, full security for all boxes is established. In comparison to the number of infringement cases and the level of importance occurred in various elections, we have to conclude, this method is a lower security than electronic voting. [3]

Another voting methods is using of ATM machines. Given that these devices directly associated with the financial discussions, they have been designed to maximize the possibility of error to zero. In the event of an error it's possible to reform and correct it. In the final days of the year that people are going to get the cash from these terminals, due to the increase in the number of applicants, each person must stay in the queue and wait for a long time to come his turn. If these devices used for voting, the result is that at the end of the day, a large number of voters can't vote. This plan is good in the cases that voting days are a week or further.[4] Also by considering the importance of identification in the elections, we need at least one person as an Installing digital .observer, standing near the ATM machine, to perform the identification phase information stands in the streets is the other way of electronic voting, these devices are much lower cost than ATM machines. Because the discussion and separation of the counting of votes to count money by the banks as quite different and the voting device does not need money counter.

Another way of voting is internet voting. By considering the current equipment there isn't solution to this issue that identification can be done via Internet and simultaneously ensuring that person would not sell his vote. Other methods of voting which will be occurred in future can vote through mobile phones, tablets and other wireless communication methods and systems. .[5]

The fundamental problem in all these cases is low possibility for running a clear election in the length of a day. Some of these cases, such as the traditional voting are possible for election in a 
day, but they aren't clear enough and also the others cases have their special problems, for example an ATM is clear but the speed is not appropriate.

\section{THE IDEA OF HOLDING A REFERENDUM WITH TWO RECEIPTS FOR EACH VOTE}

Lack of giving receipt is a criticism that often can be seen in voting systems. Election officials refrain from offering receipt to voters that shows candidate who voted, to prevent buying and selling votes. Although this issue opposes to buy and sell votes in detail but people's confirmation of the final results of the vote counting process will disappear.

In this section, we introduce a scheme that provide receipts and ensure the transparency of the election, also the possibility of buying and selling votes in this scheme is eliminated.

It is assumed that voters use computers in the Polling place, their votes are recorded in the system. In the process of recording votes, voters logged in some basic information on the system, most important of them are the national code and the selected candidate code. Software of polling produce two receipt for each of the voter as followed below:

1. Barcode receipt: This is a receipt contain a barcode that have two main features. First is that based on the barcode definition each barcode receipt should be unique and second feature is that the content of this receipt, reveals that the barcode is related to a vote of the which candidate. This receipt isn't sealed.

2. Vote key receipt: it is a symmetric key to encode four data (voter's National code , candidate's code who selected by voter, election centre code, barcode receipt's code ) The receipt is sealed by the seal of election centre.

The voter will be check the result of elections on the internet by means of barcoded receipts, obviously voter keeps the vote key receipt with himself to control in cases which he has found contradictions in votes or other existing cheats.

Anyway, the vote of voter is locked in national election centre and the key for opening it, is only in hand of voter. The locked vote (which is an encrypted text), is kept in national election centre.

\subsection{The process of recording barcode receipts in the database}

In the beginning of elections, election officials must set up database for candidates and register each barcode receipts of voters in the related database. All updates of these data bases are released during voting in the election centre website. For more security this database isn't online and just upload and update of it can be do online in a short intervals.

Each voters, moments after the votes can go to the website of election centre to open (or download) database about the list of his candidate votes. He must find his specific vote barcode in these databases. If the barcode does not exist in the database, it means, by anyway, his vote is ruined. In these cases, voters can inform the problem to the agent or relevant supervisor with selected candidate.

It is also possible that agents of candidates (given that they are following facts to be discovered), doing verification of voters receipts directly. It helps to speed up security check for elderly people or those who have not access to the internet 


\subsection{Checking the probability of selling votes election receipts}

An important issue is answering to this question: whether the barcode receipt, will show that the voter has voted to whom? In the proposed scheme, two main options are designed to prevent the buying and selling of votes.

1. Barcoded receipt is printed simply without any special stamps. Presenting this receipt is just to inform that voter has vote in election, so it does not prove that it has been issued by voting system either personally(made a fake). The election verification is proved by this barcoded receipt and cheating prevention is done by vote key receipt.

2- Immediately after registration of vote, corresponding barcode releases on central website, and the person who wants to sell his barcode cannot prove to candidate's agents that this barcode in belong to his vote. Because corresponding candidate is not sure which announced number has received by himself from the voting place computer or the seller person kept the receipt of barcodes of voters which published on the website of that voting center and regarding the identity of voters are not clear, he announced himself as owner of that vote.

So with respect to above reasons it's impossible to sell a vote without confirmation stamp. Receipt of a vote is like a simple printed page and it's not validated.

3-3- possibility of producing a barcoded receipt for two person

Voter gets his receipt from machine and goes to the voting website, he sees barcode on website unaware that this receipt is possible to produce for more than one person. It means with manipulating voting software it would be possible to print repeated receipts for a candidate.

To prevent this type of problems we propose overall people supervision on process which it's free of charge and it can help safety control of election. People can send their vote's to their candidate's sms system. By discovering even a same barcode for to voters, candidate's agents can ask explanation from election organizers about occurred problem.

Election organizers should prepare facilities to vote revising. Each voter can open his own vote box by using his own key for receipt, after revising personal boxes, there are two possibilities:

1- Barcoded receipts of protests are same. In this case infraction is occurred and organizers should have a convincing answer to this problem.

2- Barcoded receipts are different. So its necessary to check whether this different receipt registered in database or not? This would show the correctness of undergoing process in voting center.

Solving the problem of producing same barcode for more than one person, would prevent consequent fraud possibilities. For example assume your receipt is not registered in database, in this case you can decide about your vote easily by using receipt of vote key.

3-4- people reports via social networks

In some countries election organizing impose so many security problems due to some economic costs and lack of supervisory facilities so that some of loser candidate claim "we were not able to detect some probable frauds because of lack of supervisors". 
With growthing in social networks, it would be possible to share most part of supervisory process with people in form of their reports via sending barcoded receipts to the candiate's sms or email systems.

Proposed method prevents fraud by people help in two phase: 1) sending barcodes with any informing technique 2) collaboration with candidates in vote recounting. For example in the case of same receipts for two persons, people can help candidates with checking every changes in process of barcode production or results with presenting their own personal (with key) information.

Also there is possible to design and implement of some applications in virtual environments to virtual vote recounting or fraud detection. This type of networks can monitor vote recounting by controlling produced barcodes. Furthermore establishing some legislative rules and processes in barcode production process can help social networks for more powerful supervision.

\section{CONCLUSION}

Election holding in a country needs to design specific policies. If this election wants to hold just to know about global opinions about acceptance or non-acceptance of a person that would be named as "referendum". Referendum process will be differ than Senate or Municipalities election. In this paper we proposed a method to increase voting security by using 2 receipts. With keeping votes in various places and social networks controls on votes, election safety can be increased. With respect to steps of this method, the possibility of purchasing and selling votes will decrease to zero percent and all people can monitor the results at every moment. Public participation will have very important role on increasing election safety in future also it will not impose extra costs for candidates or organizers.

\section{REFERENCES}

[1] Dix A., "Electronic democracy and its implication for political privacy", 23rd International Conference of Data Protection Commissioners, September 2001, Paris,

[2] D. Balzarotti, G. Banks, M. Cova, "An Experience in Testing the Security of Real-World Electronic Voting Systems", IEEE Transactions on Software Engineering, Vol. 36, pp. 453 - 473, May 2010

[3] S.M. Jambhulkar, J.B. Chakole, P.R.Pardhi, "A Secure Approach for Web Based Internet Voting System Using Multiple Encryption", International Conference on Signal Processing and Computing Technologies(ICESC), vol 4, pp. 371-375, jan 2014

[4] Jefferson, D. and Rubin, A. and Simons, B. and Wagner, D. A Security Analysis of the Secure Electronic Registration and Voting Experiment (SERVE), Online, Available from http://www.servesecurityreport.org/, last accessed 2014.

[5] Aviel D. Rubin. Security Considerations for Remore Electronic Voting. Communications of the ACM, 45(12), 2012. 